\title{
Third East-West Philosophers' Conference
}

In an attemt to apply the work and results of the East-West Philosophers' Conferences held at the University of Hawaii in 1939 and 1949 to the general area of practical, social thought and action, the University of Hawaii will conduct a Third East-West Philosophers' Conference from June 22 to July 31, 1959, at the University of Hawaii in Honolulu, Hawaii. The theme of the conference is "EastWest Philosophy in Practical Perspective." The purpose of the conference is "to consider the practical implications of comparative philosophy for cultural institutions as a basis of world understanding and co-operation."

The unique significance of this conference lies in the belief that real understanding can be achieved only through knowledge of the fundamental convictions of the peoples of the East and West, in the effort to explore the pilosophical basis of world understanding comprehensively and intensively, and in the attempt to promote more comprehensive perspective in the field of social philosophy as well as in the more technical areas of metaphysics and methodology.

The work of the conference will be divided into six one-week sections as follows:

1. The Relation of Philosophical Theories to Practical Affairs.

2. Natural Science and Technology in Relation to Cultural Institutions and Social Practice.

3. Religion and Spiritual Values.

4. Ethics and Social Practice.

5. Legal, Political, and Economic Philosophy.

6. Conspectus of Practical Implications for World Understanding and Cooperation.

In conjunction with the conference eight special courses will be offered in the Summer Session of the University of Hawaii - two in Western philosophy, three survey courses in Asian philosophy (Buddhist philoscphy, Chinese philosophy Indian philosophy) and three comparative courses (Philosophy of Religion, Legal and Political Philosophy, and Ethics and Social Philosophy).

For further information write Charles A. Moore, Director, East-West Philosophers' Conference, University of Hawaii, Honolulu 14, Hawaii. 